\title{
Experimental Investigation of Natural Convection Heat Transfer from a Fin Array- A Review
}

\author{
Prof.S.A.Wani ${ }^{1}$, Prof.A.P.Shrotri ${ }^{2}$, Prof.A.R.Dandekar ${ }^{3}$ \\ ${ }^{1,3}$ Assistant Professor, Padmabhooshan Vasantraodada Patil Institute of Technology, Budhgaon. \\ ${ }^{2}$ Associate Professor, Padmabhooshan Vasantraodada Patil Institute of Technology, Budhgaon.
}

\begin{abstract}
Fins are commonly applied for heat management in electrical appliances such as computer power supplies or substation transformers. Vertical plate fins have been conventionally adopted to enhance the heat transfer from a vertical heated plate. The main function of these fins is not to increase the heat transfer rate itself, but to enlarge the effective heat transfer area. In order to obtain a high level of heat transfer performance with these fins, the surface area of the fins should be far larger than that of the base plate. For the enhancement of Natural convection from vertical heated plates, mostly vertical rectangular fins are used. But these fins are inapplicable for tall vertical plate. This can be explained as the boundary layer developed over the tall vertical plate becomes very thick, and the fins must be much higher than the boundary layer thickness in order to obtain a significant improvement in heat transfer. However, such high fins are no longer practical. Therefore, a new enhancing technique is needed to be developed for natural convection.

This paper discusses the efforts of earlier researchers for heat transfer enhancement in natural convection and a proposal for further investigations. In order to enhance the heat transfer, $V$-fins are to be attached to the base plate with the edges faced downstream and in a layout of an array. The V-Fins will then be blackened in order to increase the radiative heat transfer.
\end{abstract}

Keywords: Natural Convection, Fins, V-Fins, Blackened V-Fin Array

\section{INTRODUCTION}

Fins are used to transfer required quantity of heat normally if available surface is found inadequate referring to available temperature gradient. Rate of heat dissipation from a fin configuration by convection heat transfer depends on the coefficient of heat transfer and the surface area of the fins. The effective surface area can also be increased by addition of more fins to the base material in order to increase the total heat transfer from the fins. However the number of the fins should be optimized keeping in the mind the fact that addition of more fins also decreases the pitch of the adjacent fins. Using fins is one of the convenient and cheapest means to dissipate unwanted heat and it has been practiced for many engineering applications successfully. Fins are used to enhance heat transfer by convection in a wide range of engineering applications, and offer an easy means to achieve a large effective heat transfer surface area and thereby eliminating need of large primary surface area. Fins are commonly applied for efficient heat removal in electrical appliances such as computer power supplies or substation transformers. Rectangular shape fins are the most accepted type of fins owing to their low production costs and high effectiveness. Among all fins, those protruding from bases is popular Configuration because they offer economical and trouble free solution to the problem. Natural convective heat transfer is augmented by providing such protruding rectangular fins on horizontal or vertical surfaces in many electrical and electronic applications. Due to reduction in surface area available for heat dissipation and lower heat transfer coefficients of base materials, optimization of fin geometry becomes very significant in natural convection of heat. Now-a-days in electronic industries microminiaturization is a trend. The thermal design problem is the inherent hurdle in achieving higher packaging densities and becomes one of the limiting factors. Natural convection occurs due to temperature gradient which gives rise to the density difference. In fin geometry optimization some portion of this stagnant zone is utilized and its effect on other parameters are studied using various shapes and sizes by thorough investigation. Some of the material from that critical portion is removed, and is added at a suitable place which allows for more fresh air to come in the contact of the surface, it would increase the overall heat transfer coefficient ' $h$ '. In present study the fin flats are proposed to be modified by removing the central fin portion. 


\section{Literature REVIEW}

Prasolov et al. (1961), Heya et al. (1982), Bhavnani et al.(1990) have studied the heat transfer of natural convection using roughness elements of less height compared to the boundary layer thickness. It is found that no appreciable influence was observed in heat transfer and these elements have simply retarded the flow but cannot enhance the heat transfer.[1-3]

A compact high-performance heat transfer plate was devised by researchers in order to eliminate the boundary layer restrictions. Some investigators have developed horizontal partition plate and Vshaped plates.

Misumi et al. (1990) investigated on the heat transfer in the downstream region of the partition plate and observed a remarkable enhancement on exceeding the plate height beyond certain critical values, owing to the low temperature fluid inflow into the separation region. There was enhancement of $40 \%$ in heat transfer coefficient compared to the conventional fins for vertical plate fitted with $\mathrm{V}$-shaped fins. Further, it was observed that the heat transfer enhancement ratio exceeds the ratio of the surface enlargement; however the enhancement observed for horizontal partition plate and vertical fins was less as compared with V-plate [4].

A parametric study of heat transfer using the horizontal rectangular fin arrays for natural convection was done by Baskaya et al. (2000)

The effects of a wide range of geometrical parameters like spacing, height, length of the fins and temperature difference between fin and surroundings, were investigated to study the heat transfer from horizontal fin arrays. However, it became difficult for drawing conclusions owing to the no. of parameters involved. Finally it was concluded that, by only concentrating on one or two parameters, it is not possible to obtain optimum performance in terms of overall heat transfer. It is highly needed to consider the interactions among all the design parameters. This study revels significance of each of the variables as each of them produce an effect on the overall heat transfer. However it can be generally stated that the enhancement of overall heat transfer is with the increase in the height $(\mathrm{H})$, of the fin and decrease in the length $(\mathrm{L})$ of the fin [5].

Sane et al.(2008) compared the results obtained by using CFD software and the experimental results for natural convection using a horizontal rectangular notched fin arrays. For heat dissipation in natural convection, the flow patterns and the trend of heat transfer coefficient are found to be within 5\% range. It is also observed that heat transfer coefficient along with total heat flux increases with the increase in notch depth.

Chance of getting greater amount of fresh cold air (by suction into the array through a single chimney pattern) to come in contact with hot fin surface was effected by compensating the area removed from the fin at the air entry ends of the fin .The air moves inwards along the chimney profile, gets heated and thereby decreasing temperature difference between the fin and entering air. This fact makes that area near its lengthwise centre of fin relatively less useful for heat transfer. The heat transfer and the convective heat transfer coefficient can be enhanced by re-moving this area and adding at a place where it is more useful for heat transfer. CFD analysis conducted for two cases; keeping the single chimney flow pattern for both the cases, viz (a) Unnotched fin Array and (b) Fin Array with Notch of $20 \%$ and $40 \%$ area removed, reveals that the performance of notched array is better by up to $41.82 \%$ [6].

Edlabadkar et.al.(2008) performed experimental investigation on partition plate of single V-type having different included angles. The investigation is concerned with numerical analysis of the laminar air flow over a vertical base plate with $\mathrm{V}$ shape fin (the fin limb length is $0.15 \mathrm{~m}$ and width $0.05 \mathrm{~m}$ ) attached to it, using Computational Fluid Dynamics (CFD) and FLUENT with laminar viscous model. Various geometrical configurations were investigated with fin included angles $90^{\circ}, 120^{\circ}$ and $60^{\circ}$, for equal base and fin areas removing heat by natural convection for temperature difference $\theta$, varying from $30^{\circ} \mathrm{C}$ to $150^{\circ} \mathrm{C}$. It was observed that least resistance to flow separation in the upstream region was offered by the $90^{\circ} \mathrm{V}$ fin. It also offer the most effective high heat transfer zone in the downstream portion of the base plate., the maximum heat transfer enhancement $12 \%$ among the three $\mathrm{V}$-type partition plates is for $90^{\circ} \mathrm{V}$-partition plates as compared to vertical partition plate and $15.27 \%$ as compared to horizontal partition plate [7]. 
Wankhede $\boldsymbol{e}$ al. (2008) devised an experimental setup to carry out the investigation on natural and forced convections for horizontal rectangular fin array with and without inverted notch. The objective of the work was experimental determination of the heat transfer characteristics, and further extended to find out the heat transfer enhancement in the case of fin arrays mentioned earlier and analyzed the effect of different parameters of fins like length, height, spacing on heat transfer coefficient (h).

It is concluded that, the average heat transfer coefficient $\left(h_{a}\right)$ is directly proportional to percentage of area removed and about 30 to $70 \%$ rise is achieved as compared to normal fin array. The value of base heat transfer coefficient $\left(h_{b}\right)$ increases as fin spacing decreases, it reaches to an optimum, giving minimal spacing and again decreases on further reduction in spacing. For below minimal fin spacing the values of both ha and $\mathrm{hb}$ are significantly less. The value of average Nusselt number $(\mathrm{Nu})$ is directly proportional to fin spacing. The value of base Nusselt number (Nub) increases as fin spacing decreases; it reaches to its optimum value and again decreases on further reduction in spacing. [8].

Sable et al.(2010) investigated natural convection adjacent to a vertical heated plate with multiple V fins in ambient air surrounding for heat transfer enhancement.

It was concluded that as compared to conventional vertical fins, the V-type partition plates work as extended surface as well as flow turbulator. The vertical fin array restricts the heat transfer enhancement from vertical base plate owing to the fact of boundary layer thickening and subsequent interference developed over the height. The experiments were conducted with the width variation from $20 \mathrm{~mm}$ to $38 \mathrm{~mm}$ for a plane and vertical finned plates, [9].

Barhatte et al. (2012) investigated on heat transfer rate through different types of notches such as rectangular, circular, triangular, trapezoidal etc. in the fin. The plain and notched fin arrays were compared for different heat inputs. The dimensions of fin were fixed. It was concluded that heat is transfer rates through triangular notch fin are maximum as compared to other types of notches. [10].

Kharche et al. (2012) investigated on heat transfer rate for plain and notched fins of copper on vertical heated plate for the experimental work. The shape of the notch was rectangular. Comparison on the effect of heat transfer coefficient for notch and without notch fins.

From the experimental investigations it was found that the heat transfer rate in notched fins was more as compared to the plain fins. The average heat transfer coefficient for plain fin was $8.3887 \mathrm{~W} / \mathrm{m}^{2} \mathrm{~K}$ against $9.8139 \mathrm{~W} / \mathrm{m}^{2} \mathrm{~K}$ for $20 \%$ notched fins. Also the copper gives high heat transfer rate comparatively than aluminum plate.

In order to overcome the boundary layer restrictions and develop a compact high-performance heat transfer plate, some investigators have developed horizontal partition plate and V - shaped plates [11].

\section{Concluding Remarks}

Many previous researchers investigated natural convection heat transfer from the extended surfaces.

The earlier studies were mainly concerned with the heat transfer rate from the extended surfaces which differs greatly from that from the base surfaces.

The vertical fins are inapplicable to the heat transfer enhancement of a tall vertical plate, owing to the fact that the boundary layer developed over the tall plate becomes very thick. For an appreciable improvement of the heat transfer, the height of the fin must surpass the boundary layer thickness. Obviously such high fins are not practical.

As compared to conventional vertical fins, the V-type partition plates work not only as extended surface but also as flow turbulator.

For vertical plate with $\mathrm{V}$-shaped fins, the heat transfer coefficient obtained was $40 \%$ higher than the conventional fins. it was also realized that the heat transfer enhancement ratio exceeds the surface enlargement ratio ; further the enhancement obtained for horizontal partition plate and vertical fin was less than V-plate.

For horizontal V-shaped fin array with various included angle, it was concluded that the maximum convective average heat transfer coefficient is obtained for $60^{\circ} \mathrm{V}$-fin array. 


\section{SCOPE FOR FURTHER WORK}

The heat transfer rate from the extended surfaces is based on the fact that the enhancement of overall heat transfer rate is with the increase in the height $(\mathrm{H})$, of the fin and decrease in the length $(\mathrm{L})$ of the fin. However there are limitations for such optimization. The enhancement in heat transfer resulting from fin spacing does have some minimal spacing limits.

Hence, the Natural Convection heat transfer with Blackened surfaces is proposed. In order to enhance the heat transfer, V-fins will be attached to the base plate with the edges faced downstream and in a layout of an array. The V-Fins with Plate will then be blackened in order to increase the radiative heat transfer. In all, seven different configurations will be introduced for investigations. The following figures are showing some of the arrangements.

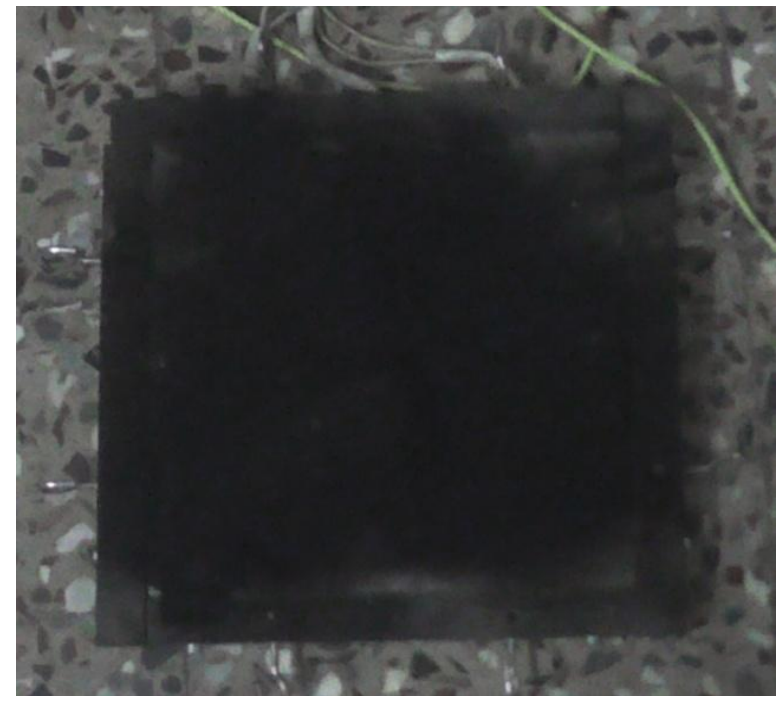

Figure1. Plain Plate with Blackened Surface

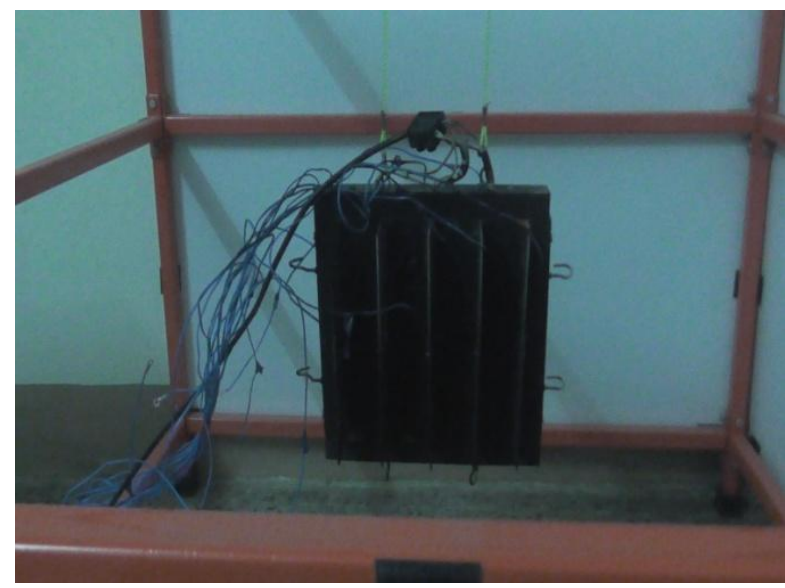

Figure2. Plain Plate with Vertical Fins Blackened Surface

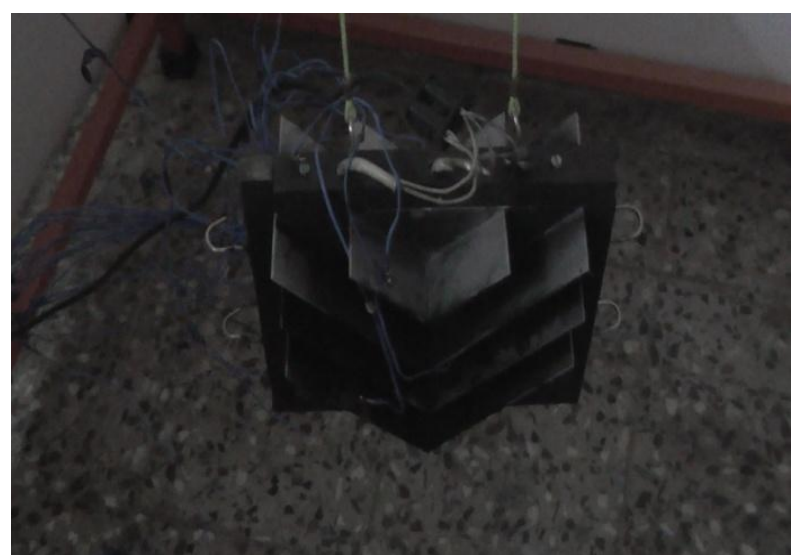

Figure3. Plain Plate with V-Fins Blackened Surface 


\section{REFERENCES}

[1] Prasolov R.S, 1961, "The effects of Surface Roughness of horizontal Cylinders on Heat transfer to air", Inzhfiz. (In Russian), 4, 3-8.

[2] Heya N., Takeuchi M., and Fujii T., 1982, "Influence of Various Surface Roughness on Free convection Heat transfer from a Horizontal Cylinder", Chem. Engg. J. Vol.23, 185-190.

[3] Bhavnani S.H., and Bergles A.E., 1990, "Effect of Surface Geometry and Orientation on Laminar Natural Convection Heat transfer from a Vertical Flat Plate with Transverse Roughness Elements", Int. J. Heat Mass Transfer, 33, 965-969.

[4] Misumi Toshiyuki and Kitamura Kenzo, 1990, "Natural Convection Heat Transfer from a vertical heated plate with a horizontal partition plates", J.S.M.E Int. J. Heat Mass Transfer, 38, 463-470.

[5] Baskaya, S, Sivrioglu, M, and Ozek, M, 2000, "Parametric Study of Natural Convection Heat Transfer from Horizontal Rectangular Fin Arrays," Int. J. Therm. Sci., 39, pp. 797-805.

[6] S.S. Sane, N.K. Sane, and G.V. Parishwad, 2008 "Computational Analysis of Horizontal Rectangular Notched Fin Arrays Dissipating Heat by Natural Convection" 5th European Thermal-Sciences Conference, The Netherlands.

[7] Edlabadkar, N.K. Sane, and G.V. Parishwad, 2008,"Computational Analysis of Natural Convection with Single V-Type Partition Plate" ,5th European Thermal Sciences Conference, The Netherlands.

[8] Wankhede,2008, "Experimental Investigation of Heat Transfer from Inverted Notch Fin Arrays (INFA) Under Natural and Forced Convections "IOSR Journal of Mechanical and Civil Engineering (IOSR-JMCE)ISSN(e) : 2278-1684, ISSN(p) : 2320-334X, PP : 14-22

[9] Sable, S. J. Jagtap, P. S. Patil , P. R. Baviskar, and S.B. Barve, 2010,"Enhancement of Natural Convection Heat Transfer on Vertical Heated Plate by Multiple V-Fin Array" IJRRAS, 5 (2), November.

[10] Barhatte,2012, "Experimental and Computational Analysis and Optimization for Heat Transfer through Fins with Triangular Notch", International Journal of Emerging Technology and Advanced Engineering, Volume 2, Issue 7 ,ISSN 2250-2459.

[11] Shivdas S. Kharche, Hemant S. Farkade,2012, "Heat Transfer Analysis through Fin Array by Using Natural Convection "International Journal of Emerging Technology and Advanced Engineering ,ISSN 2250-2459, Volume 2, Issue 4. 